\title{
Galactography with Tomosynthesis Technique (Galactomosynthesis) - Renaissance of a Method?
}

\section{Galaktografie mit Tomosynthese (Galaktomosynthese) - Renaissance einer Methode?}

(ㄷ) (i) $($ ) $\Theta$

Authors

Rüdiger Schulz-Wendtland ${ }^{1 *}$, Caroline Preuss ${ }^{2 *}$, Peter A. Fasching ${ }^{2}$, Christian R. Loehberg ${ }^{2}$, Michael P. Lux ${ }^{2}$, Julius Emons², Matthias W. Beckmann², Michael Uder ${ }^{1}$, Markus Mueller-Schimpfle ${ }^{3}$

\section{Affiliations}

1 Radiologisches Institut, Universitätsklinikum Erlangen, CCC ER-EMN, Universitäts-Brustzentrum Franken, Erlangen, Germany

2 Frauenklinik, Universitätsklinikum Erlangen, CCC ER-EMN, Universitäts-Brustzentrum Franken, Erlangen, Germany

3 Klinik für Radiologie - Klinikum Frankfurt Hoechst, DKGzertifiziertes Brustzentrum, Frankfurt am Main, Germany

Key words

breast, galactography, tomosynthesis, galactomosynthesis, ultrasound, MRI

Schlüsselwörter

Mamma, Galaktografie, Tomosynthese, Galaktomosynthese, Ultraschall, MRT

received 21.2.2018

revised 12.3.2018

accepted 18.3.2018

Bibliography

DOI https://doi.org/10.1055/a-0594-2277

Geburtsh Frauenheilk 2018; 78: 493-498 @ Georg Thieme

Verlag KG Stuttgart · New York | ISSN 0016-5751

Correspondence

Prof. Dr. med. R. Schulz-Wendtland

Universitätsklinikum Erlangen, Radiologisches Institut/

Gynäkologische Radiologie

Universitätsstraße 21-23, 91054 Erlangen, Germany

ruediger.schulz-wendtland@uk-erlangen.de

Deutsche Version unter:

https://doi.org/10.1055/a-0594-2277

\section{ABSTRACT}

Introduction For decades, conventional galactography was the only imaging technique capable of showing the mammary ducts. Today, diagnosis is based on a multimodal concept which combines high-resolution ultrasound with magnetic resonance (MR) mammography and ductoscopy/galactoscopy and has a sensitivity and specificity of up to $95 \%$. This study used tomosynthesis in galactography for the first time and compared the synthetic digital 2D full-field mammograms generated with this technique with the images created using the established method of ductal sonography. Both methods should be able to detect invasive breast cancers and their precursors such as ductal carcinoma in situ (DCIS) as well as being able to identify benign findings.

Material and Methods Five patients with pathological nipple discharge were examined using ductal sonography, contrast-enhanced 3D galactography with tomosynthesis and the synthetic digital 2D full-field mammograms generated with the latter method. Evaluation of the images created with the different imaging modalities was done by three investigators with varying levels of experience with complementary breast diagnostics (1, 5 and 15 years), and their evaluations were compared with the histological findings.

Results All 3 investigators independently evaluated the images created with ductal sonography, contrast-enhanced 3D galactography with tomosynthesis, and generated synthetic digital 2D full-field mammograms. Their evaluations were compared with the histopathological assessment of the surgical specimens resected from the 5 patients. There was 1 case of invasive breast cancer, 2 cases with ductal carcinoma in situ and 2 cases with benign findings. All 3 investigators made more mistakes when they used the standard imaging technique of ductal sonography to diagnose suspicious lesions than when they used contrast-enhanced galactography with tomosynthesis and the generated synthetic digital 2D fullfield mammograms.

Conclusion This is the first time breast tomosynthesis was used in galactography (galactomosynthesis) to create digital 3-dimensional images of suspicious findings. When used to- 
gether with the generated synthetic digital 2D full-field mammograms, it could be a useful complementary procedure for the diagnosis of breast anomalies and could herald a renaissance of this method. Compared with high-resolution ductal ultrasound, the investigators achieved better results with contrast-enhanced galactography using tomosynthesis and the generated synthetic digital 2D full-field mammograms, as confirmed by histopathological findings.

\section{ZUSAMMENFASSUNG}

Einleitung Die konventionelle Galaktografie stellte jahrzehntelang das einzige bildgebende Verfahren zur Darstellung von Milchgängen in der Brust dar. Heute verfügen wir in der Diagnostik über ein multimodales Konzept aus hochauflösendem Ultraschall, der Magnetresonanz-(MR-)Mammografie und der Duktoskopie/Galaktoskopie mit Sensitivitäten und Spezifitäten bis zu 95\%. Ziel unserer Untersuchung war es, erstmalig die Tomosynthesetechnik in der Galaktografie einzusetzen und die daraus generierten synthetischen digitalen 2-D-Vollfeld-Mammografien mit der etablierten Methode der duktusorientierten Sonografie zu vergleichen. Es sollen mit beiden Methoden invasive Mammakarzinome und deren Vorstufen wie duktale Carcinoma in situ (DCIS) sowie benigne Befunde erkannt werden.

Material und Methoden Wir führten bei 5 Patientinnen mit pathologischer Mamillensekretion sowohl eine duktusorientierte Sonografie, eine kontrastmittelunterstützte Galaktografie mithilfe der Tomosynthese in 3-D sowie auch den daraus generierten synthetischen digitalen 2-D-VollfeldMammografien durch. Die Auswertung der unterschiedlichen Untersuchungsmodalitäten erfolgte durch 3 in der komple- mentären Mammadiagnostik erfahrene Untersucher (1, 5 und 15 Jahre) und wurde mit der endgültigen Histologie korreliert.

Ergebnisse Alle 3 Untersucher beurteilten unabhängig voneinander die Bilder des duktusorientierten Ultraschalls und der kontrastmittelunterstützten Galaktografie in Tomosynthesetechnik in 3-D und den daraus generierten, synthetischen digitalen 2-D-Vollfeld-Mammografien. Die Ergebnisse wurden mit den histopathologischen Befunden der Operationspräparate korreliert, wobei sich bei den 5 Patientinnen 1 invasives Mammakarzinom, 2-mal ein duktales Carcinoma in situ (DCIS) und 2 benigne Befunde ergaben. Alle drei Untersucher lagen bei der Verdachtsdiagnose in der Standardbildgebung der duktusorientierten Sonografie seltener richtig als bei der erstmalig durchgeführten, kontrastmittelunterstützten Galaktografie in Tomosynthesetechnik und den daraus generierten, synthetischen digitalen 2-D-Vollfeld-Mammografien.

Schlussfolgerung Erstmalig wurde die Brusttomosynthese in der Galaktografie (Galaktomosynthese) eingesetzt und ermöglichte eine digitale, 3-dimensionale Darstellung von suspekten Befunden. Zusammen mit den daraus synthetisierten, digitalen 2-D-Vollfeld-Mammografien könnte dies in Zukunft eine sinnvolle Ergänzung der komplementären Mammadiagnostik sein - und eine Renaissance dieser Methode. Im Vergleich mit dem duktusorientierten Ultraschall in Hochauflösung erzielten die Untersucher mit der kontrastmittelunterstützten Galaktografie in Tomosynthesetechnik und den daraus generierten, synthetischen digitalen 2-D-Vollfeld-Mammografien bessere Ergebnisse in Korrelation mit den histopathologischen Befunden.

\section{Introduction}

Conventional galactography was first described in the 1930s by E. Ries. The contrast medium initially used was lipiodol, which was injected into secreting mammary ducts. However, lipiodol was associated with too many complications including inflammation and abscess formation, as the oily contrast medium was poorly absorbed or excreted. The first useful diagnostic results were obtained in the 1940s when water-soluble contrast media began to be used [1,2]. In the 1960s and 1970s the use of galactography was tested in larger studies, and the method was increasingly used in routine clinical practice $[1,2]$. The basic technique has not changed much since then [29]. Duct ectasias, filling defects, and duct obstruction are indirect indicators of an existing pathology, but generally they do not permit any diagnosis of the type of pathology and require subsequent histopathological examination [16,29]. Galactography has profited from advances in $\mathrm{X}$-ray technology, the use of local anesthetics, and the development of improved non-ionic contrast media.

For decades, conventional galactography (with a sensitivity and specificity of up to $95 \%$ ) [1 - 16] was the only imaging procedure capable of showing the mammary ducts.
Today, in addition to conventional galactography, diagnoses are based on a multimodal concept which includes ultrasound with high-frequency transducers $(10-18 \mathrm{MHz}$ ) (reported sensitivities and specificities of up to $91 \%)[8,10,12,13,15,17-21]$, magnetic resonance (MR) mammography (with a sensitivity and specificity of $89 \%$ and $93 \%$, respectively) [5,13,14, 19,21-23] and ductoscopy (with a sensitivity and specificity of $71 \%$ and $62 \%$, respectively) [24-26]. Sonography (which has a reported sensitivity and specificity of $91 \%)[8,10,12,13,15,17-21]$ is now generally available in all breast centers, and the increasingly common use of high-frequency transducers $(10-18 \mathrm{MHz})$ has made high-quality ductal sonography possible. Sonography also provides the option of carrying out simple, cost-effective, imageguided biopsies if findings appear to be pathological (BI-RADS ${ }^{\text {TM }}$ $4 / 5$ ). MR mammography (which has a reported sensitivity and specificity of up to 89 and $93 \%$, respectively) $[5,13,14,19,21-$ 23 ] is increasingly being used, and many centers also carry out MR-guided biopsies. The range of imaging modalities used for diagnosis also includes ductoscopy/galactoscopy (with a reported sensitivity and specificity of 71 and 62\%, respectively) [24-26] with simultaneous histological confirmation of findings.

Full-field digital mammography (FFDM) is the most important procedure for the early diagnosis of breast cancer or ductal carci- 
noma in situ (DCIS). But the superimposition of tissue structures typical for this type of projection technique often reduces the specificity and sensitivity of the mammogram. Digital breast tomosynthesis (DBT) provides sectional images not obscured by overlying structures, using a limited number of individual images from different projection angles. This removes the unwanted masking created by overlying structures. Clinical studies have shown that digital tomosynthesis has the potential to reduce the rate of patients who require repeat appointments and can increase the rate of detected carcinomas (detection and volumetry), particularly in women with dense breast tissue [27, 30].

This study used the tomosynthesis technique [27] in galactography for the first time and compared the generated synthetic digital 2D full-field mammograms [28] with the images created using the established method of ductal sonography. Both methods should detect invasive breast cancers and their precursors such as ductal carcinoma in situ (DCIS) as well as benign findings.

\section{Material and Methods}

\section{Patient population}

A total of five patients were examined at the Radiological Institute of Erlangen University Hospital and the Radiology Clinic of Frankfurt Hoechst Clinical Center. All 5 patients were examined using standard breast diagnostics which included clinical examination, breast sonography and mammography and ductal sonography. The patients also had contrast-enhanced galactography with 3D tomosynthesis, which was additionally used to generate synthetic digital 2D full-field mammograms.

Inclusion criteria to participate in the study were unilateral pathological secretions (bloody secretions or spontaneous clear/ serous, cloudy or brownish/green [not milky] secretions). Exclusion criteria were prior breast surgery, status post irradiation of the breast, or prior drug treatment.

\section{Ductal sonography, galactography, breast tomosynthesis}

Ductal sonography was carried out using a high-resolution ultrasound system (12-15 MHz), an electronic focus and a linear-array transducer (Siemens ${ }^{\mathrm{TM}}$, Acuson, Erlangen, Germany). Assessment criteria were normal mammary ducts, duct ectasias, and suspicious intraductal findings. All patients were also examined using galactography. After administering a local anesthetic and accessing the affected excretory duct, the cannula (Cook, Baesweiler, $30-\mathrm{G}$ sialography needle) was positioned and $0.1-1.5 \mathrm{ml}$ of a hydrosoluble contrast medium was injected. The secreting duct was then compressed using a swab or plaster, and a spray dressing was applied to prevent leakage of the contrast medium [29]. After this investigation each patient also had digital breast tomosynthesis, and the results were used to create synthetic digital 2D fullfield mammograms [27-28]. The mammography systems used for investigation were

1. Selenia Dimensions (Hologic Bedfort ${ }^{\mathrm{TM}} \mathrm{MA}$, USA), and

2. Amulet Innovality (Fujifilm ${ }^{\mathrm{TM}}$, Germany).
With the Selenia system, the tube was rotated in one plane; the rotation angle was $\pm 7.5^{\circ}$ and the pixel size was $70 \mu \mathrm{m}$ with a spatial resolution of 8 line pairs (Ip)/mm. The Amulet Innovality System had a standard rotation angle of $\pm 7.5^{\circ}$ (high-resolution from $\left.\pm 20^{\circ}\right)$, a pixel size of $150 / 100 \mu \mathrm{m}(100 / 50 \mu \mathrm{m})$, and a spatial resolution of $3 \mathrm{lp} / \mathrm{mm}, 5 \mathrm{lp} / \mathrm{mm}$ and $10 \mathrm{lp} / \mathrm{mm}$. The average dose used for the narrow-angle digital 2D full-field mammography was $1.70 \mathrm{mSv}$ (standard deviation 0.42), meaning that it was lower than the legal maximum of $2.5 \mathrm{mGy} /$ image [29]. The mean imaging time was 10 seconds. Synthetic digital 2D full-field mammograms were generated from the tomosynthesis data using the process software of the respective systems. The assessment criteria for both the tomosynthesis images and the synthetic digital 2D full-field mammograms generated from the tomosynthesis sequences were normal findings, duct ectasia, single filling effect, multiple filling defects, and ductal stenosis [16].

\section{Surgery and pathology}

All patients underwent ductectomy, which was performed after preoperative skin marking. Each resected specimen was sent for histopathological examination. Cases with invasive breast cancer underwent breast-conserving therapy with sentinel lymph node biopsy (SLN) in a second surgical intervention.

\section{Statistical analysis}

Evaluation of the images created by the three imaging modalities was done by 3 investigators with prior experience in the use of complementary breast diagnostics (1, 5 and 15 years). Their findings were compared with the final histological reports. As the number of cases was very small, calculating the sensitivity, specificity, PPV (positive predictive value = number of correct positive results/number of correct positive + number of false positive results) and the NPV (negative predictive value = number of correct negative results/number of correct negative + number of false negative results) was not meaningful.

\section{Results}

Ductal sonography followed by 3D digital tomosynthesis ( $\vee$ Fig. $1 \mathbf{a}$ and $\mathbf{b}$ ) with synthetic 2D full-field mammograms generated from the datasets of the galactography ( $\nabla$ Fig. 1 c) was carried out in five patients. Three investigators (with 1, 5, and 15 years' professional experience, respectively) independently evaluated the findings presented in the images.

The mean patient age was 54.2 years (youngest: 21 years; oldest: 83 years).

\section{Histopathological findings}

The definitive diagnosis based on histological examination of the resected specimens from the 5 patients was one case of invasive breast cancer, two cases with ductal carcinoma in situ (DCIS) and two cases with benign findings. 

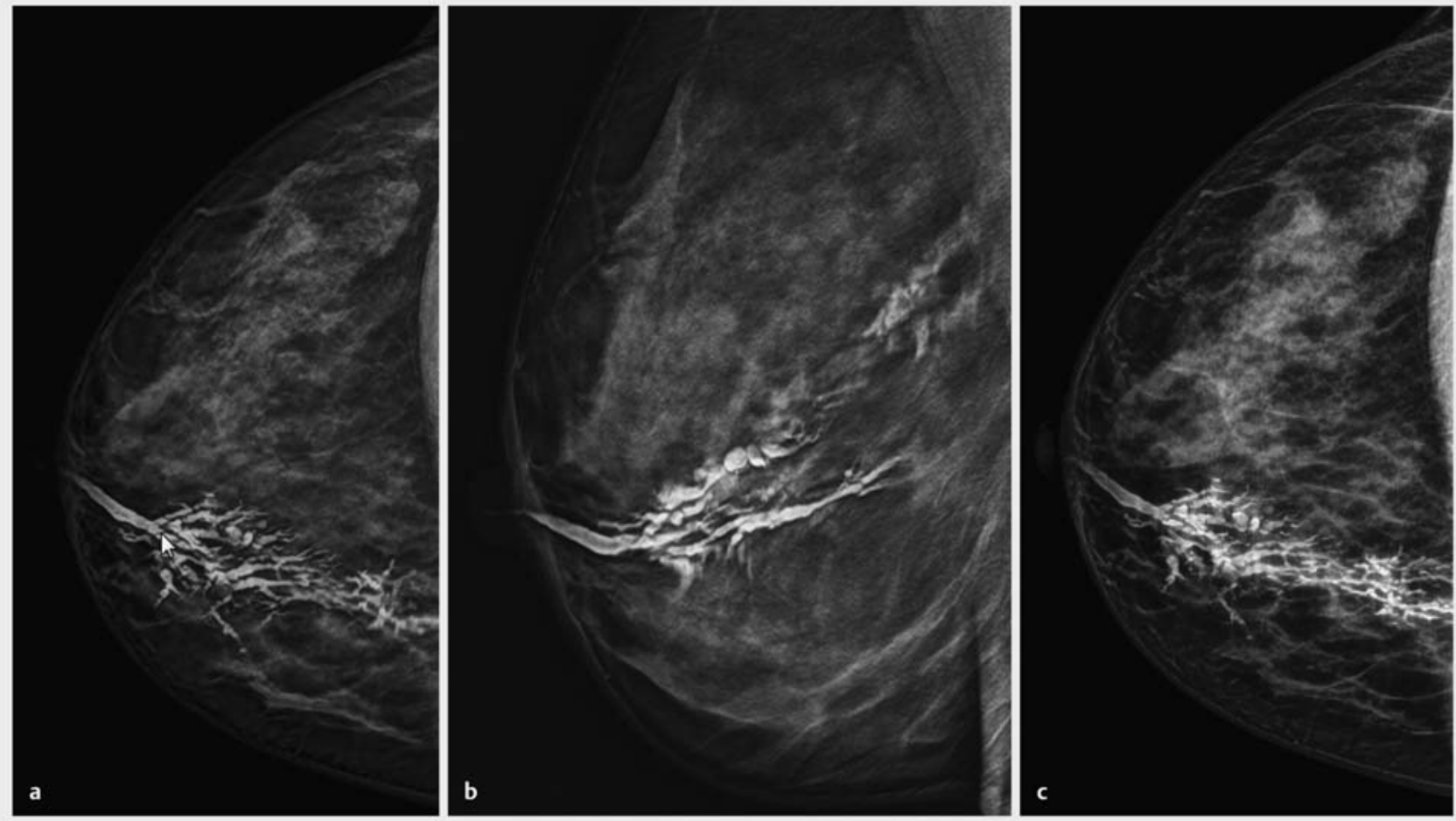

- Fig. 1 a and b Contrast-enhanced 3D galactography with tomosynthesis (DBT). a Single CC projection image of right breast; b Single ML projection image of right breast. c Synthetic digital 2D full-field CC projection mammogram of Fig. a generated from contrast-enhanced galactography with tomosynthesis; diagnosis: multiple filling defects and duct obstruction - BIRADSTM 4 [31]; Histology: extensive right breast papillomatosis.

\section{Comparison of ductal ultrasound with breast tomosynthesis and galactography and the resulting synthetic digital 2D full-field mammograms}

Investigator 1 had one year's professional experience of complementary breast diagnostics and correctly identified 3 of 5 lesions with ductal high-frequency ultrasound ( $\bullet$ Fig. 2 ) and was mistaken twice. By comparison, he made a correct diagnosis in 4 of 5 cases using breast tomosynthesis and the generated synthetic digital 2D full-field mammograms.

Investigator 2 had 5 years' professional experience of complementary breast diagnostics and correctly diagnosed 3 of 5 lesions with ductal ultrasound. Using breast tomosynthesis and the synthetic generated digital 2D full-field mammograms, 5 out of 5 diagnoses were correct.

Investigator 3 had 15 years' professional experience of complementary breast diagnostics and correctly identified 4 of 5 lesions using ductal sonography. Using breast tomosynthesis and the synthetic digital 2D full-field mammograms generated with this method, he correctly diagnosed 5 out of 5 lesions as confirmed by the final histological evaluation.

Sensitivity, specificity, positive predictive value and negative predictive value were not calculated because of the small number of cases.

\section{Discussion}

With our study we were able to show for the first time that breast tomosynthesis can be used in galactography (galactomosynthesis) to create digital three-dimensional images of suspicious findings. Together with the synthetic digital 2D full-field mammograms which can be generated with this method this represents an additional option in breast diagnostics.

We also carried out a comparison between the established diagnostic method of ductal high-frequency sonography (12$15 \mathrm{MHz}$ ) and contrast-enhanced galactography with tomosynthesis and the synthetic digital 2D full-field mammograms that can be generated with the latter method.

The comparison showed that ductal high-frequency ultrasound and the synthetic digital 2D full-field mammograms generated using contrast-enhanced galactography with tomosynthesis were approximately equivalent with respect to the correct diagnosis of suspicious findings and the final histopathological findings. Sensitivity, specificity, positive and negative predictive values were not calculated in this study because of the small number of cases.

There is currently no literature on contrast-enhanced galactography with tomosynthesis and the synthetic digital 2D full-field mammograms which can be generated with this technique.

Our study showed that when contrast-enhanced galactography with tomosynthesis were used for the evaluation of suspicious lesions together with the synthetic digital 2D full-field mammo- 


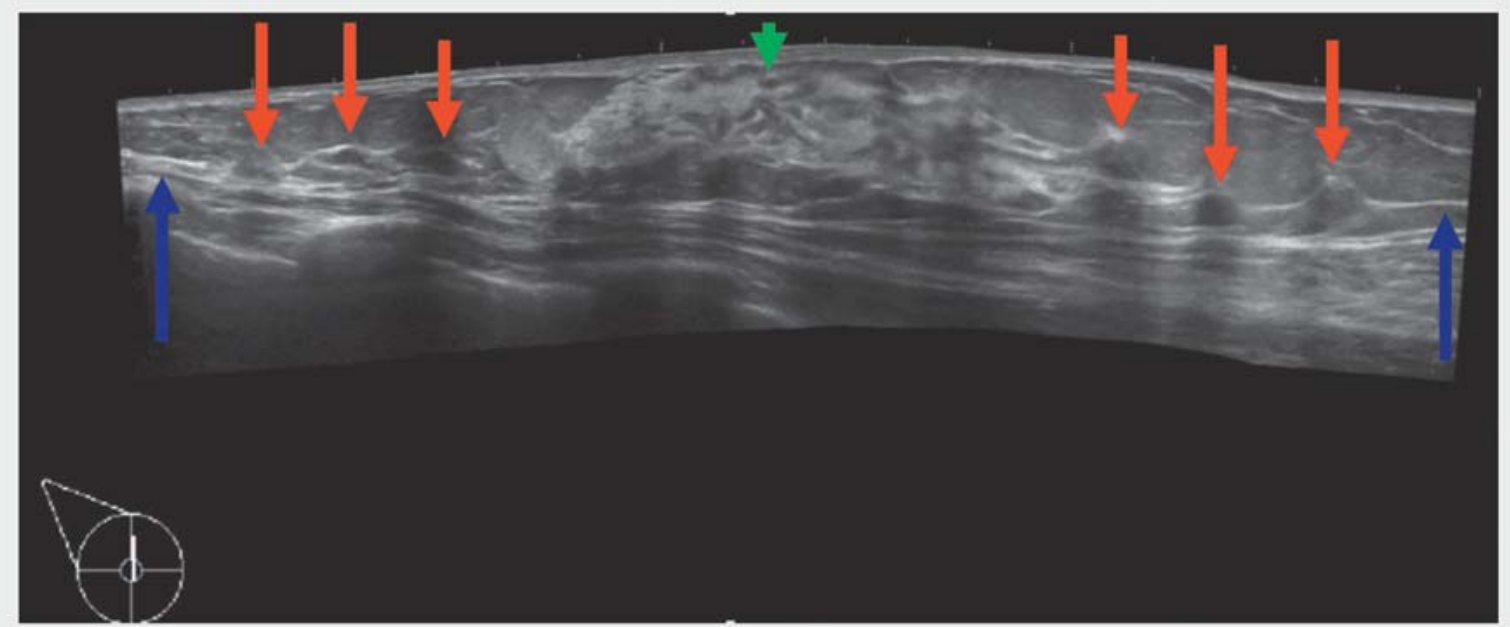

- Fig. 2 High-resolution ductal ultrasound (12-15 MHz). Multiple intraductal papillomas with duct obstruction and bloody nipple discharge (blue: duct obstruction, red: multiple intraductal papillomas, green: nipple).

grams generated with this technique, findings were more often diagnosed correctly compared to standard diagnostics based on ductal high-frequency ultrasound, as confirmed by the final histological examination. This applied to all three investigators despite the fact that their professional experience of complementary breast diagnostics differed quite considerably (1, 5, 15 years) $(\triangleright$ Table 1$)$.

This result was surprising insofar as breast tomosynthesis and contrast-enhanced galactography with tomosynthesis in particular are not procedures routinely used in breast diagnostics. By comparison, breast sonography and ductal ultrasound are standard diagnostic procedures which are routinely used, and the investigators had many years' experience in evaluating these standard images. It is not possible to compare their results with results in the literature as there is no comparative literature comparing these modalities.

The limitation of our study was the small number of investigated cases. Nevertheless, our data does highlight certain issues: 1. This first use of tomosynthesis in galactography (galactomosynthesis) tended to achieve better results compared to ductal high-frequency ultrasound in terms of proof of concept - could this lead to a renaissance of galactography?
2. This could expand the range of tomosynthesis uses in complementary breast diagnostics.

A review of the literature (PubMed) using the key words breast, mammography, ultrasound, galactography, MRI, ductography, tomosynthesis showed that no comparative study has been carried out which compared clinical examination, nipple smear cytology, ductal high-frequency sonography, galactography, MR mammography and ductoscopy and their histological correlations or even galactography with DBT (galactomosynthesis).

Our study achieved some interesting early results. The aim should now be to evaluate these results in a multicenter study. If the results obtained in our study can be confirmed in a larger patient population, then tomosynthesis and particularly contrastenhanced galactography with tomosynthesis (galactomosynthesis) and the synthetic digital 2D full-field mammograms it can generate could be a useful addition to complementary breast diagnostics and could lead to a renaissance of this method.

Our method would make it possible to reduce the number of unnecessary operations and could contribute to optimizing surgical management by using a 3-dimensional visualization of pathological processes.

- Table 1 Results for the 3 investigators: number of correct suspicious diagnoses as confirmed by histological examination of the specimens ( $\mathrm{n}=5$ ) according to the imaging modality.

\begin{tabular}{|l|l|l|}
\hline Imaging modality & $\begin{array}{l}\text { Ductal high-frequency ultrasound } \\
(\mathbf{1 2 - 1 5} \mathbf{~ M H z})\end{array}$ & $\begin{array}{l}\text { Contrast-enhanced galactography with tomosyn- } \\
\text { thesis (3D) together with synthetic digital 2D full- } \\
\text { field mammograms generated with this method }\end{array}$ \\
\hline Investigator 1 (1 year professional experience) & 3 & 4 \\
\hline Investigator 2 (5 years' professional experience) & 3 & 5 \\
\hline Investigator 3 (15 years' professional experience) & 4 & 5 \\
\hline
\end{tabular}




\section{Conflict of Interest}

The authors declare that they have no conflict of interest.

\section{References}

[1] Scheurlen K, Schnitzer A, Krammer J et al. Stellenwert der Galaktographie zur Abklärung pathologischer Sekretion in der komplementären Mammadiagnostik - Teil 1: Eine Onlineumfrage an den deutschen Brustzentren. Radiologe 2014; 54: 63-67

[2] Scheurlen K, Schnitzer A, Krammer J et al. Stellenwert der Galaktographie zur Abklärung pathologischer Sekretion in der komplementären Mammadiagnostik - Teil 2: Eine systematische Literaturanalyse. Radiologe 2014; 54: 160-166

[3] Ciatto S, Bravetti P, Berni D et al. The role of galactography in the detection of breast cancer. Tumori 1988; 74: 177-181

[4] Grillo ME, Lehmann-Willenbrock E, Gent HJ. Chromogalactography preceding ductal-lobular unit excision for nipple discharge-with special reference to diagnostic galactography and histology. Ann Chir Gynaecol 1990; 79: 6-9

[5] Krämer SC, Rieber A, Gorich J et al. Diagnosis of papillomas of the breast: value of magnetic resonance mammography in comparison with galactography. Eur Radiol 2000; 10: 1733-1736

[6] Dinkel HP, Gassel AM, Müller T et al. Galactography and exfoliative cytology in women with abnormal nipple discharge. Obstet Gynecol 2001; 97: 625-629

[7] Baitchev G, Gortchev G, Todorova A et al. Intraductal aspiration cytology and galactography for nipple discharge. Int Surg 2003; 88: 83-86

[8] Cabioglu N, Hunt KK, Singletary SE et al. Surgical decision making and factors determining a diagnosis of breast carcinoma in women presenting with nipple discharge. J Am Coll Surg 2003; 196: 354-364

[9] Funovics MA, Phillipp MO, Lackner B et al. Galactography: method of choice in pathologic nipple discharge? Eur Radiol 2003; 13: 94-99

[10] Adepoju LJ, Chun J, El-Tamer M et al. The value of clinical characteristics and breast-imaging studies in predicting a histopathologic diagnosis of cancer or high-risk lesion in patients with spontaneous nipple discharge. Am J Surg 2005; 190: 644-646

[11] Hünerbein M, Raubach M, Gebauer B et al. Ductoscopy and intraductal vacuum assisted biopsy in women with pathologic nipple discharge. Breast Cancer Res Treat 2006; 99: 301-307

[12] Gray RJ, Pockaj BA, Karstaedt PJ. Navigating murky waters: a modern treatment algorithm for nipple discharge. Am J Surg 2007; 194: 850854

[13] Grunwald S, Heyer H, Paepke S et al. Diagnostic value of ductoscopy in the diagnosis of nipple discharge and intraductal proliferations in comparison to standard methods. Onkologie 2007; 30: 243-248

[14] Morrogh M, Morris EA, Liberman L et al. The predictive value of ductography and magnetic resonance imaging in the management of nipple discharge. Ann Surg Oncol 2007; 14: 3369-3377
[15] Hamed ST, Abdo MH, Ahmed HH. Breast discharge: ultrasound and Doppler evaluation. J Egypt Natl Canc Inst 2008; 20: 262-270

[16] Montroni I, Santini D, Zucchini G et al. Nipple discharge: is its significance as a risk factor for breast cancer fully understood? Observational study including 915 consecutive patients who underwent selective duct excision. Breast Cancer Res Treat 2010; 123: 895-900

[17] Grunwald S, Bojahr B, Schwesinger G et al. Mammary ductoscopy for the evaluation of nipple discharge and comparison with standard diagnostic techniques. J Minim Invasive Gynecol 2006; 13: 418-423

[18] Vargas HI, Vargas MP, Eldrageely K et al. Outcomes of clinical and surgical assessment of women with pathological nipple discharge. Am Surg 2006; 72: 124-128

[19] Choudhury S, Isomoto I, Hyashi K. Magnetic resonance imaging features of breasts in patients with nipple discharge. Bangladesh Med Res Counc Bull 2008; 34: 44-47

[20] Liu GY, Lu JS, Shen KW et al. Fiberoptic ductoscopy combined with cytology testing in the patients of spontaneous nipple discharge. Breast Cancer Res Treat 2008; 108: 271-277

[21] Morrogh M, Park A, Elkin EB et al. Lessons learned from 416 cases of nipple discharge of the breast. Am J Surg 2010; 200: 73-80

[22] Schwab SA, Uder M, Schulz-Wendtland R et al. Direct MR galactography: feasibility study. Radiology 2008; 249: 54-61

[23] Wenkel E, Janka R, Uder M et al. Does direct MR galactography have the potential to become an alternative diagnostic tool in patients with pathological nipple discharge? Clin Imaging 2011; 35: 85-93

[24] Ohlinger R, Stomps A, Paepke S et al. Ductoscopic detection of intraductal lesions in cases of pathologic nipple discharge in comparison with standard diagnostics: the German multicenter study. Oncol Res Treat 2014; 37: 628-632

[25] Schulz-Wendtland R, Aichinger U, Krämer S et al. [Galactoscopy-is it a new interventional method for breast diagnosis?]. Rofo 2002; 174: 1015-1017

[26] Schulz-Wendtland R, Meier-Meitinger M, Adamietz B et al. Digitale Galaktoskopie der 2. Generation. Geburtsh Frauenheilk 2011; 71: 255-259

[27] Schulz-Wendtland R, Beckmann MW, Fasching PA et al. Tomosynthese. Gynäkol Prax 2015; 39: 521-534

[28] Choi JS, Han BK, Ko EY et al. Comparison between two-dimensional synthetic mammography reconstructed from digital breast tomosynthesis and full-field digital mammography for the detection of $\mathrm{T} 1$ breast cancer. Eur Radiol 2016. doi:10.1007/s00330-015-4083-7

[29] S3-Leitlinie Früherkennung, Diagnose, Therapie und Nachsorge des Mammakarzinoms, Version 4.0. 2017. AWMF Registernummer: 032045OL. Online: http://www.leitlinienprogramm-onkologie.de/leitlinien/ mammakarzinom/; Stand: 12.02.2018

[30] Rafferty EA, Durand MA, Conant EF et al. Breast cancer screening using tomosynthesis and digital mammography in dense and nondense breasts. JAMA 2016; 315: 1784-1786

[31] Morris EA, Comstock C, Lee C et al. ACR BI-RADS ${ }^{\text {TM }}$ - Atlas der Mammadiagnostik. Berlin, Heidelberg: Springer-Verlag; 2016 